\title{
INFLUENCE OF DIFFERENT ADHESIVE SYSTEMS ON THE PULL-OUT BOND STRENGTH OF GLASS FIBER POSTS
}

\author{
Luciana Mendonça da SILVA ${ }^{1}$, Andréa Mello de ANDRADE ${ }^{2}$, Melissa Fernanda Garcia MACHUCA ${ }^{3}$, \\ Paulo Maurício Batista da SILVA ${ }^{4}$, Ricardo Virgolino C. da SILVA ${ }^{1}$, Maria Cecília VERONEZI ${ }^{5}$
}

\begin{abstract}
1- DDS, Specialist in Restorative Dentistry, Hospital for Rehabilitation of Craniofacial Anomalies of University of São Paulo (HRAC/USP), Bauru, SP, Brazil; Graduate Student, Department of Operative Dentistry, Dental Materials and Endodontics, Bauru School of Dentistry, University of São Paulo, Bauru, SP, Brazil.

2- DDS, Specialist in Restorative Dentistry, Hospital for Rehabilitation of Craniofacial Anomalies of University of São Paulo (HRAC/USP), Bauru, SP, Brazil; Graduate Student, Department of Dental Materials, São Paulo School of Dentistry, University of São Paulo, São Paulo, SP, Brazil.

3- DDS, Specialist in Restorative Dentistry, Hospital for Rehabilitation of Craniofacial Anomalies of University of São Paulo (HRAC/USP), Bauru, SP, Brazil.

4- DDS, Specialist in Restorative Dentistry, Hospital for Rehabilitation of Craniofacial Anomalies of University of São Paulo (HRAC/USP), Bauru, SP, Brazil, Graduate Student, Department of Prosthodontics, Bauru School of Dentistry, University of São Paulo, Bauru, SP, Brazil. 5- DDS, MSc, PhD, Associate Professor, Department of Restorative Dentistry, University of the Sacred Heart, Bauru, SP, Brazil.
\end{abstract}

Corresponding address: Dra. Luciana Mendonça da Silva - Rua Joaquim Fidelis, 7-65, apto. 23, Vila Altinópolis - 17012-180 - Bauru - SP Brazil - Phone: 5514 3214-4807 / 5514 9162-6177 - Fax: 5514 3214-3036 - e-mail: luciana.mendonca@gmail.com

Received: September 4, 2007 - Modification: November 27, 2007 - Accepted: January 28, 2008

\begin{abstract}
$\Gamma_{\text {his }}$ dentin with a resin cement (RelyX ARC - 3M/ESPE) associated with two different adhesive systems (Adper Single Bond - 3M/ ESPE and Adper Scotchbond Multi Purpose (MP) Plus - 3M/ESPE), using the pull-out test. Twenty single-rooted human teeth with standardized root canals were randomly assigned to 2 groups $(n=10)$ : G1- etching with $37 \%$ phosphoric acid gel $(3 \mathrm{M} /$ ESPE) + Adper Single Bond + \#1 post (Reforpost - Angelus) + four \#1 accessory posts (Reforpin - Angelus) + resin cement; G2- etching with 37\% phosphoric acid gel + Adper Scotchbond MP Plus + \#1 post + four \#1 accessory posts + resin cement. The specimens were stored in distilled water at $37^{\circ} \mathrm{C}$ for 7 days and submitted to the pull-out test in a universal testing machine (EMIC) at a crosshead speed of $0.5 \mathrm{~mm} / \mathrm{min}$. The mean values of bond strength (kgf) and standard deviation were: G1- 29.163 \pm 7.123 ; G2- $37.752 \pm 13.054$. Statistical analysis (Student's t-test; $\alpha=0.05$ showed no statistically significant difference ( $<0.05$ ) between the groups. Adhesive bonding failures between resin cement and root canal dentin surface were observed in both groups, with non-polymerized resin cement in the apical portion of the post space when Single Bond was used (G1). The type of adhesive system employed on the fiber post cementation did not influence the pull-out bond strength.
\end{abstract}

Key words: Dental dowels. Dentin-bonding agents. Tensile strength.

\section{INTRODUCTION}

The maintenance of teeth in the mouth is a primary goal of dentistry. In cases of large destruction, due to caries or accidental fracture, preservation of tooth remainder is a major concern, even if the pulp tissue has been affected. Endodontics is a specialty that aims to provide, under certain conditions, the maintenance of teeth whose pulp vitality has been irreversibly compromised ${ }^{13}$.

Endodontically treated teeth can be restored either directly or indirectly, and usually require the use of an intracanal retainer, such as metallic post and core. One of the main reasons for the use of intracanal metallic post and core, though mistaken, is reinforce the root structure ${ }^{13}$. In addition to being unaesthetic, metallic posts present low resilience and do not accompany the modulus of elasticity of dentin. The development of resin posts reinforced with glass or carbon fiber came to minimize the difference between the modulus of elasticity of the restorative material and that of root remnant, thus avoiding root fractures. Fiber posts are considered an alternative to metallic post and core in the restoration of endodontically treated teeth ${ }^{12}$.

Posts are usually cemented with resin cements associated with adhesive systems, which has increased the interest in studying bonding to root canal dentin 7 . The association of adhesive systems to resin cements promotes a more effective union to root dentin, being thus a relevant factor in adhesive cementation. Proper selection of the adhesive system might directly influence the retention of intracanal posts ${ }^{6,9}$.

It is known that autopolymerizing resins are not 
compatible with most conventional 2-step etch-and-rinse adhesive systems. This is due to the fact that these adhesive systems have in their composition an acidic monomer that, when in contact with autopolymerizing resins, react with tertiary amines and inhibit the activation of the polymerization reaction ${ }^{14}$. Such incompatibility also occurs with dual or chemically cured resin cements, and is also very common during fiber post cementation with resin cements. In the apical region, the adhesive system is not completely polymerized by light activation, and residual unreacted acidic monomers might interfere with the union with the cement. The durability of adhesive cementation depends on the interaction between the adhesive system and the root dentin, the resin cement and the post ${ }^{8}$.

This in vitro study evaluated the tensile bond strength of glass fiber posts cemented to root dentin with a resin cement associated with two different adhesive systems, using the pull-out test.

\section{MATERIALAND METHODS}

Twenty extracted single-rooted human teeth were used in this study, after approval by the Ethics in Research Committee of Hospital for Rehabilitation of Craniofacial Anomalies of University of São Paulo (HRAC/USP) (\#022/ 2005-UEO-CEP).

The root canals were prepared and obturated with guttapercha cones and Sealer AH 26 endodontic sealer (Dentsply Ind. e Com. Ltda., Rio Janeiro, RJ, Brazil). The crowns were sectioned coronally $2 \mathrm{~mm}$ from the cementoenamel junction with a \#3203 diamond bur (KG Sorensen, São Paulo, SP, Brazil) positioned perpendicularly to the long axis of the tooth under copious water cooling. Roots were then prepared for post insertion. The canal space of each root was standardized and enlarged with diamond burs \#4138 and \#4137 (KG Sorensen) to a final depth of $13 \mathrm{~mm}$ from the cervical surface. The specimens were randomly assigned to 2 groups $(n=10)$ based on the types of adhesive system used in association with Rely X ARC (3M/ESPE, St. Paul, MN, USA) dual cured resin cement: Group 1 - Adper Single Bond (3M/ESPE); Group 2 - Adper Scotchbond Multi Purpose (MP) Plus (3M/ESPE).

In both groups, one main \#1 fiber-post (Reforpost; Angelus, Londrina, PR, Brazil) (1.1 mm diameter) and four accessory \#1 fiber-posts (Reforpin; Angelus) were prepared following the manufacturer's instructions. They were cleaned with alcohol and then silanated (Silano Angelus) for $1 \mathrm{~min}$. The adhesive systems of each group were applied on the posts and light-cured for $20 \mathrm{~s}$ with a halogen light (Optilight Plus; Gnatus, Ribeirão Preto, SP, Brazil).

Root dentin were etched with $37 \%$ phosphoric acid (3M/ ESPE) for $15 \mathrm{~s}$, rinsed with water for $30 \mathrm{~s}$ and dried with absorbent paper points, for both groups. Adhesive systems were applied with a microbrush according the manufacturers' instructions.

After preparation of root dentin, the resin cement was mixed following the manufacturer's recommendations and placed with a lentulo spiral drill into the canal. Finally, the main post was inserted in the canal followed by four accessory posts and light-cured for $40 \mathrm{~s}$ through the fiber posts. Once the posts were placed, the coronal portion was reconstructed with composite resin (Filtek Z-250; 3M/ESPE), using a cylindrical stainless steel mold, in such a way to allow the performance of the pull-out test (Figure 1). Tooth surface was neither etched nor treated with adhesive, before

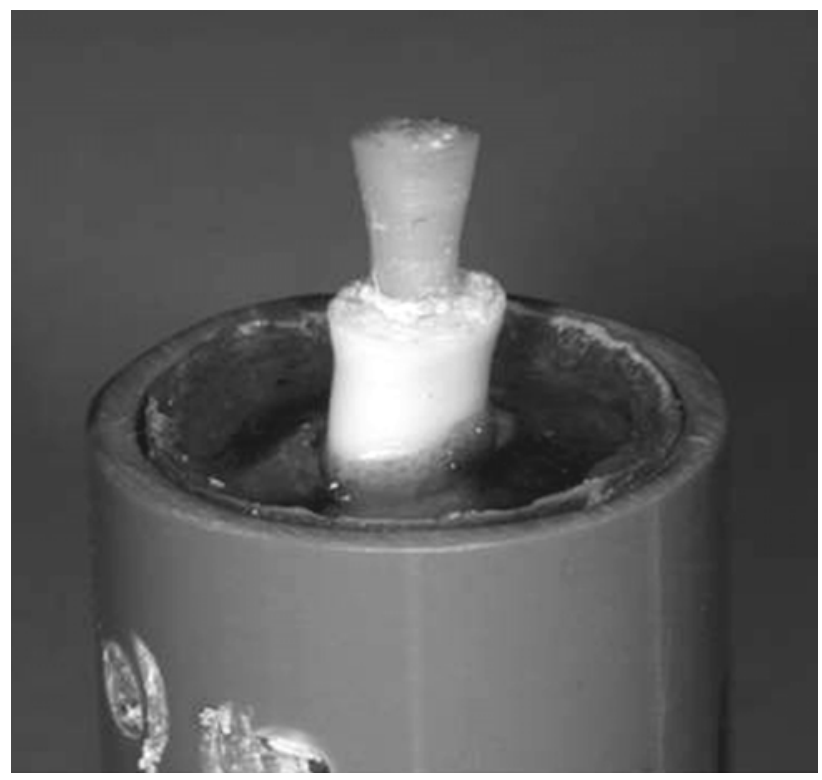

FIGURE 1- Specimen after post cementation and coronal reconstruction

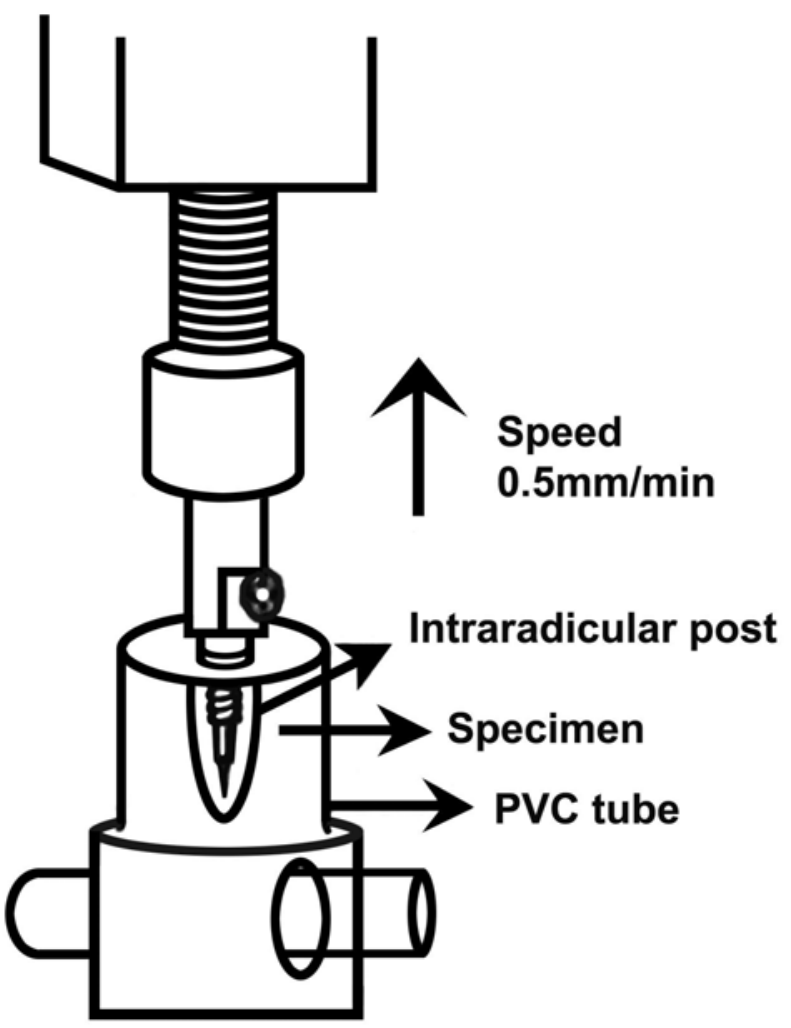

FIGURE 2- Schematic presentation of the pull-out test, showing the machine and the specimen 
coronal reconstruction with composite resin.

Teeth were stored in distilled water at $37^{\circ} \mathrm{C}$ for $24 \mathrm{~h}$, and then embedded in epoxy resin using PVC cylinders as molds. After 1 week, the specimens were submitted to a pull-out test in a universal testing machine (Emic DL500; Emic Equipamentos e Sistemas de Ensaios, São José dos Pinhais, PR, Brazil) at a cross-head speed of $0.5 \mathrm{~mm} / \mathrm{min}$ (Figure 2).

Data were analyzed statistically by Student's t-test at $5 \%$ significance level.

\section{RESULTS}

The mean values of tensile bond strength (kgf) and standard deviation were: G1-29.163 \pm 7.123 ; G2-37.752 \pm 13.054 . No statistically significant difference $(p>0.05)$ was observed between the groups.

Fiber posts cemented with resin cement RelyXARC and Adper Scotchbond MP Plus (3M ESPE) (G2) and Adper Single Bond (3M ESPE) (G1) showed similar tensile bond strength.

\section{DISCUSSION}

The bonding characteristics of prepared root dentin may vary in terms of the optimal moisture content required for application of some etch-and-rinse adhesive systems, the peculiar hydration conditions of root canal dentin due to pulp removal, the type of agent used for surface conditioning, the ability to achieve a reasonable degree of conversion when light-cured adhesive systems are polymerized at the entrance of post spaces, and potential for relief of polymerization shrinkage stresses during the setting of resin cements. There is also the action of endodontic irrigants, such as sodium hypochlorite and hydrogen peroxide, eugenol-containing sealers, and the heat generated from warm gutta-percha compaction techniques, which may influence the quality of intraradicular dentin hybridization. The chemical and physical properties of posts are variables that can also be included $d^{7,11}$.

In order to evaluate the retention of fiber posts cemented with resin cement, the main focus of this study was directed to the application of adhesive systems with different characteristics to the root dentin walls. The tested materials were a two-step etch-and-rinse adhesive system with acid $\mathrm{pH}$, which could influence negatively the polymerization of the dual-cured resin cement, and a three-step etch-and-rinse adhesive system that, as found in literature, would not influence the polymerization. Except for distilled water, no irrigant was used to avoid any interference in the bonding process.

Cavity configuration factor ( $\mathrm{C}$-factor) is defined as the ratio of the bonded surface area in a cavity to the unbonded surface area ${ }^{4}$. In root canals, the C-factor is highly unfavorable and contributes to maximize the polymerization stress of resin cements along the root canal walls. With light-cured materials, the curing stress generated in areas of high C-factors may be so intense that the composite resin layer detaches from the dentin walls, thus creating interfacial gaps $^{7,9}$. The volumetric shrinkage ranges from 1.5 to $5 \%$, resulting on internal stresses that are transferred to the dentin/resin interface as pull-out forces ${ }^{5}$. In high C-factors areas, self- and slow-curing materials can reduce stresses on the bonding interface by allowing better flow of the resin cement and relief of polymerization shrinkage ${ }^{2,15}$. Alster, et al. ${ }^{1}$ (1997) showed that the difficulty in resin cement setting within the canal space generates stresses at the bonding interface.

In this study, root canal diameter was standardized before post cementation. Accessory posts of the same manufacturer were used to minimize the quantity of resin cement and Cfactor and to promote a better frictional retention with dentin walls, which mitigates the influence of volumetric shrinkage and $\mathrm{C}$-factor.

According to Pirani, et al. ${ }^{11}$ (2005), it is most likely that the clinical success of bonded fiber posts is predominantly due to frictional retention to post space walls, rather than to adhesive bonding. This frictional retention may occur due to water sorption that induces expanding of resin cement ${ }^{10}$.

Although no significant difference was observed between the pull-out bond strengths of the groups, Group 1 specimens (Adper Single Bond) presented non-polymerized resin cement in apical portion, in agreement with Tay, et al. ${ }^{14}$ (2003), who showed an incompatibility between acidic monomers present in the outer surface of oxygen-inhibited layer of the adhesive system and tertiary amines of the resin cement that was not completely polymerized. In addition, the post space depth usually exceeds the depth of cure achieved by most light-curing units, which is an issue of concern when a light-cured adhesive system is used for bonding to radicular dentin ${ }^{11}$.

Hybridization of intraradicular dentin, as shown by Pirani, et al. ${ }^{11}$ (2005), is a phenomenological manifestation of resin infiltration following smear layer dissolution and partial root dentin demineralization. This hybridization is not essential for the integrity of coronal sealing or resistance to dislodgement of restorations, which may be one of the reasons for the lack of statistically significant difference between the groups evaluated in the present study.

The non-uniform adaptation of the adhesive material or its incomplete polymerization, both related to the difficult access to root canal space, may account for the lower bond strengths of the adhesive cements to the middle and apical root dentin ${ }^{7}$.

The use of adhesive systems associated with resin cements and pre-fabricated posts is limited by factors inherent to the contemporary materials as well as to the characteristics of the substrates to which they are applied ${ }^{2}$. In the present study, two different light-cured adhesive systems used for adhesive cementation of glass fiber posts to root canal walls presented similar behavior under pullout testing. 


\section{CONCLUSIONS}

The type of adhesive system employed on the fiber post cementation did not influence the pull-out bond strength.

\section{ACKNOWLEDGEMENTS}

We are grateful to Dr. Maria Teresa Atta for advice and assistance with data analysis. We thank ANGELUS Produtos Odontológicos (Brasil) and 3M/ESPE (Brasil) for supplying the products used in this study.

\section{REFERENCES}

1- Alster D, Feilzer AJ, Gee AJ, Davidson CL. Polymerization contraction stress in thin resin composite layers as a function of layer thickness. Dent Mater. 1997;13(3):146-50.

2- Bouillaguet S, Troesch S, Wataha JC, Krejci I, Meyer JM, Pashley DH. Microtensile bond strength between adhesive cements and root canal dentin. Dent Mater. 2003;19(3):199-205.

3- Carvalho RM, Pereira JC, Yoshiyama M, Pashley DH. A review of polymerization contraction: the influence of stress development versus stress relief. Oper Dent. 1996;21(1):17-24.

4- Feilzer AJ, Gee AJ, Davidson CL. Setting stresses in composite resin in relation to configuration of the restoration. J Dent Res. 1987;66(11):1636-9.

5- Ferracane JL. Developing a more complete understanding of stresses produced in dental composites during polymerization. Dent Mater. 2005;21(1):36-42.

6- Ferrari M, Mannocci F. A "one-bottle" adhesive system for bonding a fibre post into a root canal: a SEM evaluation of the post-resin interface. Int Endod J. 2000;33(4):397-400.

7- Goracci C, Tavares AU, Fabianelli A, Monticelli F, Raffaelli O, Cardoso PC, et al. The adhesion between fiber posts and root canal walls: comparison between microtensile and push-out bond strength measurements. Eur J Oral Sci. 2004;112(4):353-61.

8- Hofmann N, Papsthart G, Hugo B, Klaiber B. Comparison of photo-activation versus chemical or dual-curing of resin-based luting cements regarding flexural strength, modulus and surface hardness. J Oral Rehab. 2001;28:1022-8.

9- Mannocci F, Bertelli E, Watson TF, Ford TP. Resin-dentin interfaces of endodontically-treated restored teeth. Am J Dent. 2003;16(1):2832 .

10- Ortengren U, Wellendorf H, Karlsson S, Ruyter IE. Water sorption and solubility of dental composites and identification of monomers released in an aqueous environment. J Oral Rehabil. 2001;28(12):1106-15.

11- Pirani C, Chersoni S, Foschi F, Piana G, Loushine RJ, Tay FR, et al. Does hybridization of intraradicular dentin really improve fiber post retention in endodontically treated teeth? J Endod. 2005;31(12):891-94.

12- Schwartz RS, Robbins JW. Post placement and restoration of endodontically treated teeth: a literature review. J Endod. 2004;30(5):289-301.
13- Shillinburg HT, Hobo S, Whitsett LD, Jacobi R, Bracket SE. Fundamentals of fixed prosthodontics. Carol Stream;Ilinois: Quintessence Publishing Company; 1997.

14- Tay FR, Pashley DH, Yiu CK, Sanares AM, Wei SH. Factors contributing to the incompatibility between simplified-step adhesives and chemically-cured or dual-cured composites. Part I. Single-step self-etching adhesive. J Adhes Dent. 2003;5(1):27-40.

15- Tay FR, Loushine RJ, Lambrechts P, Weller RN, Pashley DH. Geometric factors affecting dentin bonding in root canals: a theoretical modeling approach. J Endod. 2005;31(8):584-9. 